\title{
EFFECT OF MODIFIED ULTRAFILTRATION ON HEMODYNAMICS IN PEDIATRIC CARDIAC SURGERY AT ARMED FORCES INSTITUTE OF CARDIOLOGY/ NATIONAL INSTITUTE OF HEART DISEASES (AFIC/NIHD)
}

\author{
Muneeb Ur Rehman, Tariq Rao*, Naila Niaz**, Shahid Nafees*, Naseem Azad, Muhammad Shoaib Umar* \\ Armed Forces Post Graduate Medical Institute/National University of Medical Sciences (NUMS) Rawalpindi Pakistan, *Armed Forces \\ Institute of Cardiology/National Institute of Heart Disease (AFIC/NIHD)/National University of Medical Sciences (NUMS) Rawalpindi \\ Pakistan, **University of Lahore, Lahore Pakistan
}

\begin{abstract}
Objective: To observe the effect of modified ultrafiltration on hemodynamics of pediatric patients.

Study Design: A descriptive cross-sectional study.

Place and Duration of Study: Pediatric Cardiac Surgery department, AFIC/NIHD Rawalpindi, from Jun 2019 to Dec 2019.

Methodology: A total of 60 pediatric patients were included undergoing open-heart surgery with cardiopulmonary bypass, having age $\leq 6$ years and weights $\leq 15 \mathrm{~kg}$. To assess hemodynamics parameters observed were pre modified ultrafiltration and post modified ultrafiltration measurements of haemoglobin level, systolic pressure, diastolic pressure, central venous pressure and the number of transfusions given after off-bypass. The data was entered and analyzed in SPSS-23.

Results: The pre-operative mean $\mathrm{Hb}$ level of the 60 sampled patients was $12.08 \pm 2.89 \mathrm{~g} / \mathrm{dl}$. The findings taken pre modified ultrafiltration and post modified ultrafiltration of haemoglobin level was $(9.91 \pm 0.91 \mathrm{~g} / \mathrm{dl}$ and $13.09 \pm$ $1.38 \mathrm{~g} / \mathrm{dl}, p<0.05)$ after an average filtration of $370.83 \pm 66.56 \mathrm{ml}$ of the filtrate. The mean of systolic pressure was $(61.3 \pm 2.01 \mathrm{mmHg}$ and $70.68 \pm 1.76 \mathrm{mmHg}, p<0.05)$, diastolic pressure was $(49.95 \pm 1.35$ and $59.7 \pm 6.85, p<0.005)$, Central Venous Pressure was $(10.07 \pm 1.18$ and $9.9 \pm 1.09, p>0.005)$ compared pre modified ultrafiltration and post modified ultrafiltration respectively.

Conclusion: The study concluded that modified ultrafiltration has a significant impact on haemoglobin levels after bypass, decreases the allogenic transfusions and also improve the hemodynamics of the patient.
\end{abstract}

Keywords: Blood pressure, Blood volume, Central venous pressure, Cardiac surgical procedures, Diastole, edema, Hemodynamics, Hemoglobins, Modified ultrafiltration, Systole. This is an Open Access article distributed under the terms of the Creative Commons Attribution License (http://creativecommons.org/licenses/by/4.0), which
permits unrestricted use, distribution, and reproduction in any medium, provided the original work is properly cited.

\section{INTRODUCTION}

Since 1953, the first time of usage of cardiopulmonary bypass and the heart-lung machine, there had been a lot of challenges and modifications in techniques to improve outcomes of cardiopulmonary bypass, patient safety, and perioperative care ${ }^{1}$. One of these challenges is the hemodilution which is necessary during $\mathrm{CPB}$, which is the use of large volumes of perfusateto prime the circuit, to improve oxygenation during cardiopulmonary bypass by reducing the viscosity of blood and reduce the need of banked blood thus decreasing the post-transfusion com-

Correspondence: Ms Naila Niaz, AFIC/NIHD, AFNS, Near Romi Park Rawalpindi Pakistan plications ${ }^{2-4}$. However, with all these benefits accompanies the disadvantages of hemodilution as well which includes hypotension, hypoxia, hypocoagulation and decreased colloid oncotic pressure, which leads to interstitial oedema during cardiopulmonary bypass ${ }^{5}$. Ultrafiltration can be used to combat the undesirable disadvantages of hemodilution ${ }^{6}$.

Ultrafiltration is a widely used technique to reverse hemodilution where excess plasma water and solutes are filtered out of the blood across a semipermeable membrane driven by positive transmembrane hydrostatic pressure ${ }^{7}$. Using ultrafiltration during cardiac surgery to alleviate the adverse effects of CPB, particularly those related to hemodilution, has become common ${ }^{8,9}$. 
There are three techniques of ultrafiltration used before, during and after $\mathrm{CPB}$ procedures, which ispre bypass ultrafiltration (Pre-BUF), conventional ultrafiltration (CUF) and modified ultrafiltration (MUF) respectively.

In 1991, Naik et al, studied and introduced MUF for pediatric patients so that the remaining blood of the extracorporeal circuits were ultrafiltrated and transfused to the patients while still being cannulated and attached to the extracorporeal circuit. MUF enables to concentrate and transfer nearly all of the circuit contents to the patient without the risk of hypervolemia, while the circuit remains primed with the crystalloid solution. One disadvantage of MUF is that it requires the patient to remain cannulated for 10 to 20 minutes after CPB termination, and, to maintain the integrity of the extracorporeal circuit, protamine may not be administered. Duringa subsequent study, Naik et al, conducted a prospective randomized trial comparing a MUF group to nonfiltered controls. The author noted decreased blood loss, fewer blood transfusions, and an increase in arterial blood pressure, particularly in the low-temperature and low-flow patients, while achieving a post-MUF hematocrit of $40 \% 10,11$.

In contrast toconventional ultrafiltration (CUF), modified ultrafiltration (MUF) is performed after discontinuation of $\mathrm{CPB}$ and is independent of circuit volume. Because of this technical difference, more fluid can often be removed with MUF than with CUF, assuming that no or minimal additional volume is added to the circuit during CUF. Some studies have investigated the potential advantages of MUF that it is associated with reduced blood loss and lactate levels ${ }^{12-14}$. Some studies have supported the use of modified ultrafiltration as it reduces the level of Interleukin-6 which is known as a pro-inflammatory cytokine in the acute phase of inflammation and recommended MUF to be used on pediatric patients as a routine intervention ${ }^{15-17}$. The objective of this study was to observe the effect of MUF on hemodynamics in pediatric patients.

\section{METHODOLOGY}

Institutional consent was taken from the Institutional ethics committee, Armed Forces Institute of Cardiology (AFIC/NIHD) and permission from the Department of Cardiac Perfusion, AFIC/NIHD Rawalpindi with Letter No: 29/8/R \& D/2019/17. The sample size was calculated with the anticipated frequency of $6 \%$, using Raosoft sample size calculator, at $95 \%$ confidence interval and 5\% margin of error sample size calculated was 60 . All thepatients undergoing openheart surgery with $\mathrm{CPB}$ with congenital heart diseases regardless of age and gender were included in the study with weight $\leq 15 \mathrm{~kg}$ and age $\leq 06$ years. The exclusion criteria included off-pump cases, patients with surgery of multiple stages, emergency casesand reopen cases. When the patient was weaned off from $\mathrm{CPB}$, the volume remaining in the extracorporeal circuit was returned to the patient in concentrated form by removing excess of water using hemoconcentrator. The hemoconcentrators used during the study were Sorin and Medica. The protocols of the procedure MUF is to remove the excess of water according to the SOPs of AFIC/NIHD, which is $30 \mathrm{ml} / \mathrm{kg}$. The ideal MUF time is 10 to 15 minutes, but it varies depending upon the surgeon's preference and the patient's condition. During MUF, average MUF volume of $370.83 \pm 66.56 \mathrm{ml}$ was also taken from the aorta through the aortic cannula and after filtration, the concentrated red cells returned to the patient through the venous cannula. The variables of haemoglobin, systolic, diastolic and central venous pressure pre MUF and post MUF were noted.

\section{Data Analysis}

Data were coded and entered in Microsoft excel 2010 and Statistical Package for Social Science (SPSS version 23). Data were analyzed such as frequency, mean, standard deviation of quantitative variables were obtained. To assess the effect of MUF on haemodynamics of pediatric patients, the values of haemoglobin, systolic, diastolic and central venous pressure were 
compared using paired t-test pre MUF and post MUF respectively.

\section{RESULTS}

Total samples of 60 patients were included in the study to determine the effects of MUF. The patients included in the study were $\leq 15 \mathrm{~kg}$ in weight. The male-female ratio $34 / 26$, mean height, weight and BSA of our study sample was

Table-I: Demographic variables.

\begin{tabular}{l|c}
\hline Variables & Mean \pm SD, $\%$ \\
\hline Body Surface Area $(\mathrm{BSA})\left(\mathrm{m}^{2}\right)$ & $0.503 \pm 0.11$ \\
\hline Height $(\mathrm{cm})$ & $87.08 \pm 12.67$ \\
\hline Weight $(\mathrm{kg})$ & $10.76 \pm 3.12$ \\
\hline Males & $\mathrm{n}=34,56.7 \%$ \\
\hline Females & $\mathrm{n}=26,43.3 \%$ \\
\hline Table-II: Mean of variables; pre MUF and post MUF. \\
\hline Pressures (mmHg) & $\begin{array}{c}\text { Mean } \pm \text { SD } \\
\text { (mmHg) }\end{array}$ \\
\hline Pre-operative Hb Level $(\mathrm{g} / \mathrm{dl})$ & $12.08 \pm 2.89$ \\
\hline MUF Volume $(\mathrm{ml})$ & $370.83 \pm 66.5$ \\
\hline Pre MUF Hb $(\mathrm{g} / \mathrm{dl})$ & $9.91 \pm 0.91$ \\
\hline Post MUF Hb $(\mathrm{g} / \mathrm{dl})$ & $13.09 \pm 1.38$ \\
\hline Pre MUF Systolic Pressure & $61.3 \pm 2.01$ \\
\hline Post MUF Systolic Pressure & $70.68 \pm 1.76$ \\
\hline Pre MUF Diastolic Pressure & $49.95 \pm 1.35$ \\
\hline Post MUF Diastolic Pressure & $59.7 \pm 6.85$ \\
\hline Pre MUF CVP & $10.07 \pm 1.18$ \\
\hline Post MUF CVP & $9.9 \pm 1.09$ \\
\hline Table-II: Table of association &
\end{tabular}

Table-III: Table of association.

\begin{tabular}{l|c|c}
\hline Pairs & T-value & $p$-value \\
\hline $\begin{array}{l}\text { Pre MUF Hb level- } \\
\text { Post MUF Hb Level }\end{array}$ & 28.731 & $<0.0001$ \\
\hline $\begin{array}{l}\text { Pre MUF Systolic } \\
\text { Pressure- Post MUF } \\
\text { Systolic Pressure }\end{array}$ & 27.978 & $<0.0001$ \\
\hline $\begin{array}{l}\text { Pre MUF Diastolic } \\
\text { Pressure- Post MUF } \\
\text { Diastolic Pressure }\end{array}$ & 10.552 & $<0.0001$ \\
\hline $\begin{array}{l}\text { Pre MUF CVP- Post } \\
\text { MUF CVP }\end{array}$ & 0.691 & $>0.0001$
\end{tabular}

${ }^{*}$ Paired $t$-test

$87.08 \pm 12.67 \mathrm{~cm}, 10.76 \pm 3.12 \mathrm{~kg}$ and $0.503 \pm 0.11$ $\mathrm{m}^{2}$ respectively.

The pre-operative $\mathrm{Hb}$ levels mean was $12.08 \mathrm{~g} / \mathrm{dl} \pm 2.89 \mathrm{~g} / \mathrm{dl}$. The mean pre-MUF $\mathrm{Hb}$ was $9.91 \pm 0.91 \mathrm{~g} / \mathrm{dl}$ and the mean post-MUF $\mathrm{Hb}$ was $13.09 \pm 1.38 \mathrm{~g} / \mathrm{dl}$ after filtration of average fluid about $370.83 \pm 66.56 \mathrm{ml}$. After an average
MUF of $370.83 \pm 66.56 \mathrm{ml}$, the rise in mean $\mathrm{Hb}$ level is $3.19 \mathrm{~g} / \mathrm{dl}$. The mean of systolic pressure was $61.3 \pm 2.01 \mathrm{mmHg}$ and $70.68 \pm 1.76 \mathrm{mmHg}$, Diastolic pressure was $49.95 \pm 1.35$ and $59.7 \pm$ 6.85, Central Venous Pressure was $10.07 \pm 1.18$ and $9.9 \pm 1.09$ compared pre MUF and post MUF respectively.

Paired t-test has been applied on pre and post values of $\mathrm{Hb}$ level, systolic pressures, diastolic pressures and CVP. There exists strong sig-

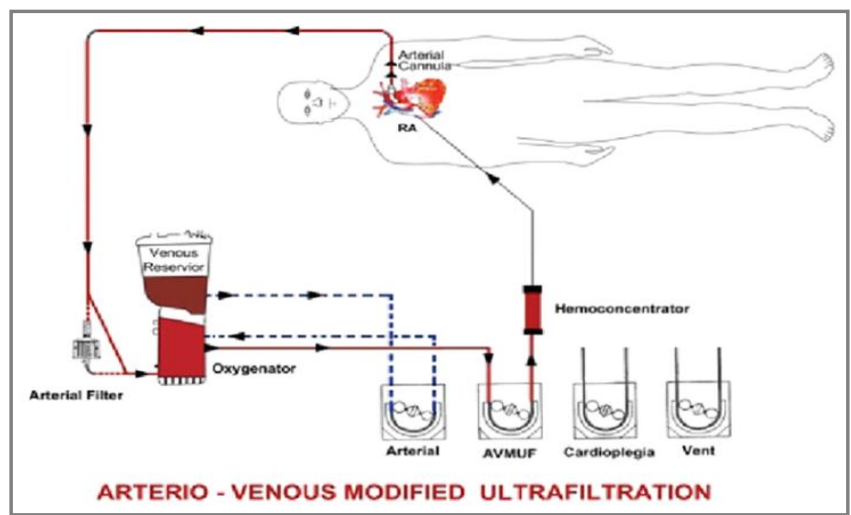

Figure-1: The circuit for modified ultrafiltration during open heart surgery.

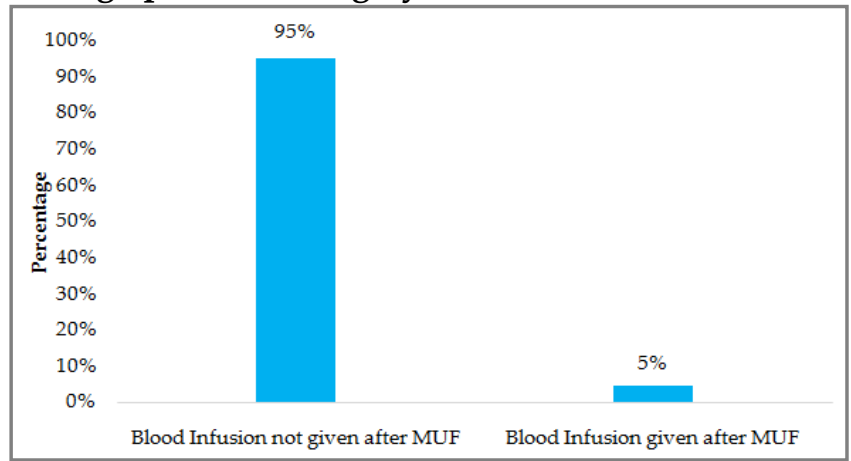

Figure-2: Bar Chart showing the utility of MUF in combating need of blood transfusion after CPB.

nificant difference between pre and post MUF systolic and diastolic pressures as represented $p$-value, while no significant difference exist for CVP pre and post MUF. Out of 60 patients, only 3 (5\%) patients were given blood infusion in OT after $\mathrm{CPB}$ due to excessive bleeding. The majority of patients do not receive blood infusion after MUF.

\section{DISCUSSION}

The primary purpose of modified ultrafiltration after CPB is to manage the volume by remo- 
ving the excess water and concentrate the cellular elements and proteins in the blood in pediatric patients. But the electrolytes and other solutes are also removed in equal concentration to the patient's plasma water. Modified ultrafiltration has shown to decrease postoperative blood loss and transfusion requirements, increases in arterial blood pressure and cardiac output, improved pulmonary function, reduced postoperative ventilator requirement and fewer days in the intensive care unit (ICU) ${ }^{18}$.

The present study aimed to elucidate the effects of MUF on haemoglobin levels, systolic, diastolic and central venous pressure comparing pre-MUF with post-MUF and postoperatively number of transfusion were observed. MUF resulted in immediate improvement in hemodynamics.

In 2 previous studies, the effects of MUF on pediatric patients were analyzed ${ }^{1013}$, however, the population of patients was heterogeneous. The present study essentially holds the same messages as the previous two studies did ${ }^{10,13}$.

Jia et al, concluded that MUF does not improve oxygenation but in the present study, it was observed that there is an improvement in arterial blood pressure after MUF and reduction in central venous pressure thus improving perfusion and oxygenation ${ }^{19}$.

Timpa et al, in 2016 conducted a study on CUF and MUF group and he concluded that implementing multidisciplinary bleeding and transfusion protocol significantly decreases perioperative blood product transfusion and also improves some bleeding outcomes ${ }^{20}$. The present study is comparable with these conclusions. We observed that very few patients required transfusion after MUF and that the hematocrit levels raised by $8-10 \%$ approximately after applying MUF in the sixty patients. And that the number of transfusions reduced significantly after cardiopulmonary bypass due to the usage of MUF.

Similar results were concluded in Netherland by Golab et al, in 2015, but applied conventional ultrafiltration only. The study found that the use of conventional ultrafiltration allowed achieving higher hematocrit levels at the end of the operation and without additional transfusions of allogenic blood ${ }^{21}$. The results of this study are comparable with our study, but we had observed the effect of modified ultrafiltration after cardiopulmonary bypass in pediatric patients yielding similar results. There are a large number of studies which compared CUF effects with MUF effect however in our study we did not compare the CUF with MUF as the CUF is done according to the attending perfusionist who decide applying or not applying CUF to the patient, taking circulating volume and actual hematocrit at the start of $\mathrm{CPB}$ into account, together with assumed results during perfusion ${ }^{14}$. In 2018, Milovanovic et al, compared MUF and CUF and divided the patients into two groups. They concluded that conventional ultrafiltration provides adequate hemoconcentration and modified ultrafiltration is better to reduce post-operative transfusion but requires more fresh frozen plasma. Present study corroborates with the study that modified ultrafiltration reduces the post-operative transfusions ${ }^{22}$.

\section{CONCLUSIONS}

Dealing with the hemodilution in pediatric patients during $\mathrm{CPB}$ is challenging. In the present study, we concluded that post MUF, immediate improvement in hemodynamics occurs and $\mathrm{Hb}$ level raises, which results in reduced allogenic infusions postoperatively. Although MUF indeed contributed in better patient outcome by reducing transfusions, this sole perfusion strategy is not enough to deal with hemodilution. To improve postoperative course of pediatric open-heart surgeries, further refinements from surgery, anesthesia and postoperative management are therefore essential to achieve better outcomes after openheart surgery in pediatric patient.

\section{CONFLICT OF INTEREST}

This study has no conflict of interest to be declared by any author.

\section{REFERENCES}

1. Romaine-Davis A. John Gibbon and his heart-lung machine. Texas Heart Instit J 1992; 19(3): 245. 
2. Manrique AM, Vargas DP, Palmer D, Kelly K, Litchenstein SE. The effects of cardiopulmonary bypass following pediatric cardiac surgery. Critical Care of Children with Heart Disease: Springer 2020. p. 113-29. [Internet] https://link.springer.com/ chapter/10.1007/978-3-030-21870-6_10.

3. Solem JO, Tengborn L, Steen S, Lührs C. Cell saver versus hemofilter for concentration of oxygenator blood after cardiopulmonary bypass. Thoracic cardiovasc surg 1987; 35(01): 42-47.

4. Bojan M. Recent achievements and future developments in neonatal cardiopulmonary bypass. Pediat Anesthe 2019; 29(5): 414-25.

5. Myers A. Postoperative effects of conventional ultrafiltration on adult cardiac surgery patients: Milwaukee School of Engineering; 2018. https://www.semanticscholar.org/paper/ Postoperative-Effects-of-Conventional-on-AdultMyers/0b75ec15b072aadfb0647c5e4e7a1df 9928d191a.

6. Wang S, Palanzo D, Ündar A. Current ultrafiltration techniques before, during and after pediatric cardiopulmonary bypass procedures. Perfusion 2012; 27(5): 438-46.

7. Gravlee GP, Davis RF, Hammon J, Kussman B. Cardiopulmonary Bypass and Mechanical Support: Principles and Practice: Lippincott Williams \& Wilkins; 2015. https://www.ovid.com/ product-details.4874.html.

8. Zakkar M, Guida G, Angelini GD. Modified ultrafiltration in adult patients undergoing cardiac surgery. Interac Cardiovasc Thoracic Surg 2015; 20(3): 415-21.

9. Ziyaeifard M, Alizadehasl A, Massoumi G. Modified ultrafiltration during cardiopulmonary bypass and postoperative course of pediatric cardiac surgery. Res Cardiovasc Med 2014; 3(2): e17830-35.

10. Naik S, Knight A, Elliott M. A prospective randomized study of a modified technique of ultrafiltration during pediatric openheart surgery. Circulation 1991; 84(5 Suppl): III422-31.

11. Naik S, Knight A, Elliott M. A successful modification of ultrafiltration for cardiopulmonary bypass in children. Perfusion 1991; 6(1): 41-50.

12. Papadopoulos N, Bakhtiary F, Grün V, Weber C, Strasser C, Moritz A. The effect of normovolemic modified ultrafiltration on inflammatory mediators, endotoxins, terminal complement complexes and clinical outcome in high-risk cardiac surgery patients. Perfusion 2013; 28(4): 306-14.

13. Ziyaeifard M, Alizadehasl A, Aghdaii N, Rahimzadeh P, Masoumi G, Golzari SE. The effect of combined conventional and modified ultrafiltration on mechanical ventilation and hemodynamic changes in congenital heart surgery. J Res Medical Sci Official J Isfahan Uni Med Sci 2016; 21(1): 113-16.

14. Mohanlall R, Adam J, Nemlander A. Venoarterial modified ultrafiltration versus conventional arteriovenous modified ultrafiltration during cardiopulmonary bypass surgery. Annals Saudi Med 2014; 34(1): 18-30.

15. Curi-Curi PJ, Alanis EA, Calderón-Colmenero J, CervantesSalazar JL, Pavón RR, Ramírez-Marroquín S. Impact of Modified Ultrafiltration in Congenital Heart Disease Patients Treated with Cardiopulmonary Bypass. Congenit Heart Dis 2018; 1(1): 49.

16. Pérez-Vela J, Ruiz-Alonso E, Guillén-Ramírez F, García-Maellas M, Renes-Carreño E, Cerro-García M, et al. ICU outcomes in adult cardiac surgery patients in relation to ultrafiltration type. Perfusion 2008; 23(2): 79-87.

17. Bierer J, Stanzel R, Henderson M, Sett S, Horne D. Ultrafiltration in Pediatric Cardiac Surgery Review. World J Pediat Congenit Heart Surg 2019; 10(6): 778-88.

18. Sever K, Tansel T, Basaran M, Kafalı E, Ugurlucan M, Ali Sayın $\mathrm{O}$, et al. The benefits of continuous ultrafiltration in pediatric cardiac surgery. Scandinavian Cardiovasc J 2004; 38(5): 307-11.

19. Jia Z, Teng Y, Liu Y, Wang H, Li Y, Hou X. Influence of highflow modified ultrafiltration on brain oxygenation and perfusion during surgery for children with ventricular septal defects: a pilot study. Perfusion 2018; 33(3): 203-08.

20. Timpa JG, O'Meara LC, Goldberg KG, Phillips JP, Crawford JH, Jackson KW, et al. Implementation of a multidisciplinary bleeding and transfusion protocol significantly decreases perioperative blood product utilization and improves some bleeding outcomes. J Extra-corporeal Technol 2016; 48(1): 11-18.

21. Golab H, Kissler J, De Jong P, van de Woestijne P, Takkenberg J, Bogers A. Clinical outcome and blood transfusion after infant cardiac surgery with a routine use of conventional ultrafiltration. Perfusion 2015; 30(4): 323-31.

22. Milovanovic V, Bisenic D, Mimic B, Ali B, Cantinotti M. Reevaluating the Importance of Modified Ultrafiltration in Contemporary Pediatric Cardiac Surgery. J Clin Med 2018; 7(12): 498-10 